Journal of Business and Management Studies (JBMS)

ISSN: 2709-0876

DOI: $10.32996 / \mathrm{jbms}$

Journal Homepage: www.al-kindipublisher.com/index.php/jbms

\title{
Impact of Covid-19 Pandemic on Financial Inclusion and Digital Adoption
}

\author{
Safa SEN ${ }^{1} \mathbf{8} \triangle$ and Sara Almeida de Figueiredo ${ }^{2}$ (iD \\ ${ }^{12} \mathrm{PhD}$ Student, the University of Miskolc, Department of Finance. Miskolc, Hungary \\ $\triangle$ Corresponding Author: Safa SEN, E-mail: safasen2@gmail.com
}

ARTICLE INFORMATION

Received: July 12, 2021

Accepted: August 20, 2021

Volume: 3

Issue: 2

DOI: $10.32996 / j b m s .2021 .3 .2 .11$

\section{KEYWORDS}

Economic Development, eCommerce, Financial Literacy, DESI

\section{ABSTRACT}

Digitalization is an inevitable fact due to increasing technology and the environment that challenges the status-quo of the traditional transactional systems. Especially during the Covid-19 pandemic, the adoption rate of eCommerce and digital transactions has increased significantly. In this research paper, we used eCommerce data of Hungary, Austria, Greece, and Sweden and their DESI index for 2017 to 2020 in order to understand the background of events which shows that the covid-19 pandemic had a significant impact on people's perception of the day-by-day transactions and that the economic development of a country has a profound impact on the financial inclusion metrics and digitalization appetite of their citizens. Our main findings show that curfews during the pandemic significantly influence the volume of eCommerce transactions and DESI Index rankings are substantially linked with real-life matters.

\section{Introduction}

Covid-19 has opened a new era and had a significant effect on our lives. It altered not only the business models but also the way people work and students' study. Most of the businesses converted to the home office since the beginning of the pandemic and most of the schools turned into remote education where students joined classes online. In other words, covid-19 has become an unfortunate event but, on the contrary, played a significant role for digital adoption to be boosted due to changes in the way we live.

During the covid-19 pandemic, various sectors have been drastically affected, especially the tourism and entertainment sectors due to country-wise lockdowns and aviation due to a drastic decrease in flights tickets and travel bans. Furthermore, demand for the sectors whose business models are based on online services skyrocketed. For instance, during the pandemic, the demand for eCommerce services demonstrated a remarkable increase while curfews played an important role for that matter. We will be discussing later the impact of the curfews on eCommerce however; we can say that it has an observable impact. However, it is also important to state that the eCommerce sector was the highest demand during the pandemic and the leisure sector with online streaming such as Netflix and Spotify became the most demanded products and services. As for the students and working professionals, online meeting programs such as MS Teams and Zoom became most demanded.

Considering these facts, in this paper, we will mainly seek answers for the following questions: how covid-19 has affected the financial inclusion factors of society? What are the demographics behind mobile and internet transactions? What are the responses of the customers to the pandemic, considering age differences?

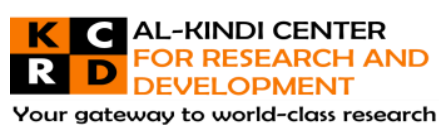

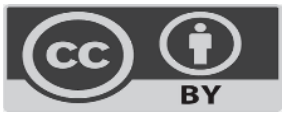

Published by Al-Kindi Center for Research and Development. Copyright (c) the author(s). This open access article is distributed under a Creative Commons Attribution (CC-BY) 4.0 license 
By answering the previously mentioned questions will try to explain the behavioral side of the pandemic on digital adoption. Therefore, we will also seek answers about what drives digital adoption in selected countries and our suggestions to boost it.

However, it is important to state that this area could be further researched when there are new data available for covid19 pandemic period while, the number of available datasets is currently shallow.

\section{Literature Review}

OECD defines electronic commerce as a catalytic effect by stating that it will serve to accelerate and diffuse more widely changes that are already underway in the economy, such as the reform of regulations, the establishment of electronic links between businesses (EDI), the globalization of economic activity, and the demand for higher-skilled workers (OECD, 1999).

Sixun Liu (2013) mentions that the evolution of e-commerce has led to the development of some emerging industries, such as logistics, and an increase of job opportunities in sectors related to Information Technology, thus stimulating the consuming behavior of the population.

The Rawabet Center's report (2018) states that the advantage of e-commerce is that it reduces time and effort, facilitates access to foreign markets, helps economic growth, and improves exports and production.

Moreoever, it is essential to state that the successful adoption of e-commerce is strongly related to the population's digital inclusion and financial literacy. In that sense, European Commission (2007) explains Financial Literacy as the "capability of consumers and small business owners to understand retail financial products to make informed financial decisions".

Furthermore, Lusardi and Mitchell (2014) define financial literacy as a combination of cognitive ability and investment in human capital related to understanding financial decisions. Poor financial literacy has been linked to lower rates of financial planning for retirement, increased mortgage default, lower participation in the stock market, and increased likelihood of taking out high-cost loans.

While financial literacy is correlated with standard demographics such as education and cognitive ability, a substantial proportion of the variation in financial literacy cannot be explained by observable characteristics.

Another definition of Financial literacy is defined by Krechovská (2015), as a kind of understanding of the financial world, which leads households and firms to correct judgment, effective decision-making, and relevant behavior in the area of finance".

Kovacs and Tertak (2019) stated an economic approach that points out the increasing importance of financial literacy regarding a constantly variant global economy and its effects on the population's economic situation and well-being and bringing as a good example the fact that prolonged effects of the 2008 financial crisis were noticed to have a high correlation with poor financial knowledge.

Furthermore, Demirguc-Kunt et al. (2017) define financial inclusion as having a deposit or transaction account at a bank or other financial service provider to make and receive payments as well as storing or saving money. Furthermore, financial inclusion also involves access to appropriate credit from formal financial institutions, in addition to the use of insurance products that enable people to alleviate financial risks such as fire, flood, or crop damage (Demirguc-Kunt et al., 2017)

Stavytskyy et al. (2019) used the panel regression technique on DESI data and their result concluded that a $1 \%$ increase in the consumption index results in about 0.2 increase in the DESI, and an increase in unemployment by $1 \%$ leads to about 0.2 DESI decline

Bánhidi et al. (2020) used statistical methods to measure DESI Index. They stated that DESI dimensions are strongly correlated, they can be reduced to two principal components covering the same scope of measurement, and there is a causality mapping the variables' relationship. Furthermore, they 
concluded the usefulness and effectiveness of the DESI overall index or weighted aggregate score and presented a more subtle mapping and ranking of EU countries in the DESI dimensions.

\section{Methodology}

In this article, we used the eCommerce dataset retrieved from the Digital 2021 Global Overview Report for the Digitalization and eCommerce statistics for the selected countries in order to assess the impact of the Covid19 pandemic. Moreover, we imported DESI scores for Hungary, Austria, Greece, Sweden, and EU Average for between 2017 and 2020 to understand their year-on-year growth and compare the results with digitalization statistics reports covering the Covid19 period. The criteria applied to the country selection, based on the DESI scores of each country. We took EU Average as an indicator and decided to choose four countries, where two countries perform above and two that perform below the EU average. This way, we will try to understand four different aspects of the economic and sociological levels of the selected countries. We selected Sweden as a top performer country in the Index, Austria as slightly above the EU Average, Hungary as slightly lower than the EU Average, and Greece as one of the worst performers.

Furthermore, our second criteria are to select countries with different Sovereign Credit Ratings since we would like to understand if economic strength and stability level is aligned with consumer digitalization skills. As it can be seen below, we have 4 countries with different DESI and Credit Rating Score. Sweden performs in the top three in the index and their credit rating is Prime. Austria ranks 14 th in the Index and has a High-Grade credit rating score. Hungary's rank is the DESI is 22 with a Lower Medium Grade credit rating. Finally, Greece is 28th in the DESI with a Speculative credit rating. Table :1 Desi Ranks and Credit Ratings of the Selected Countries:

\begin{tabular}{|c|c|c|l|}
\hline Countries & DESI Rank & S\&P Sovereign Credit Rating & Meaning of the Rate \\
\hline Sweeden & 3 & AAA & Prime \\
\hline Austria & 14 & AAt & High Grade \\
\hline Hungary & 22 & BBB & Lower Medium Grade \\
\hline Greece & 28 & BB & Speculative \\
\hline
\end{tabular}

Source: Owners own elaboration.

In Section 4, We will initially assess the Global outlook of Covid19 impact on eCommerce and its adoption. Furthermore, we will break down eCommerce adoption into two parts as mobile and computer, to understand the demographics and their choices. In Section 5 we will briefly introduce DESI and afterwards, we will compare country performance between 2017-2020 with visualized results of each country.

Furthermore, we will benchmark financial inclusion factors along with eCommerce related performance metrics of each country during the covid19 pandemic, and in section 6 , we will provide the results where we will try to link DESI Index results and progress of each country with eCommerce adoption data which was retrieved during Covid19 pandemic in order to answer the questions we previously mentioned in this research. 
Global eCommerce Adoption during Covid19

Figure 1: eCommerce Transaction Index: From January 2020 to December 2020

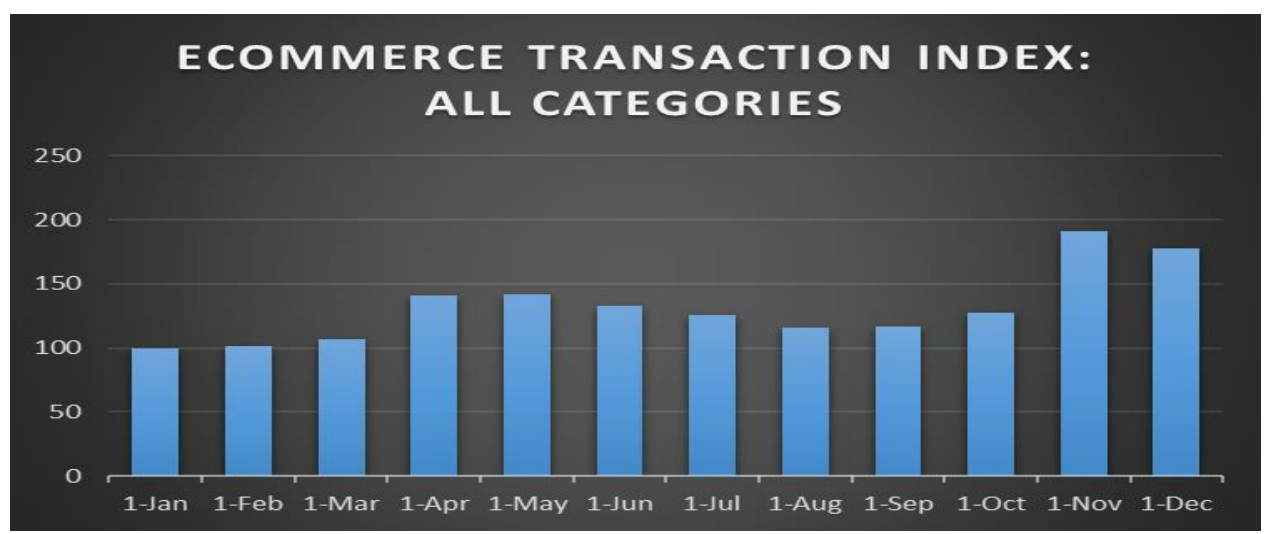

SOURCE: Hootsuite \& We Are Social (2021), "Digital 2021 Global Digital Overview,"

Figure I show eCommerce transactions that occurred between January to December 2020. We can see that number of eCommerce transactions has increased nearly 80 percent in one year period. On the other hand, we can see deviations from one month to another due to the lockdowns during the pandemic.

From March 2020 to April 2020 there is a nearly 30 to 35 percent increase in eCommerce transactions; however, during summer, when lockdowns were slightly eased, the number of transactions nearly dropped to almost its March 2020 level.

This leads to the conclusion that consumers would reduce eCommerce shopping if the pandemic would end today; however, during the next lockdown period, which is the end of September and the beginning of October, we can still see the uptrend in e-commerce transactions.

As people use eCommerce, though, consumers get more and more hands-on experience in eCommercerelated transactions. This leads to our second hypothesis that digital literacy and usage of technological products have increased significantly during the pandemic. We will address this in the upcoming sections.

\section{eCommerce Adoption by Age via Mobile}

It is important to break down eCommerce transactions into two parts to understand the demographics of the adoption and create some open-ended questions that could be a research topic for researchers whose area of interest is eCommerce.

In figure 2, we can see that eCommerce via Mobile is mostly adopted by the young generation while the adoption rate declines as the age go up.

Figure 2: eCommerce Via Mobile

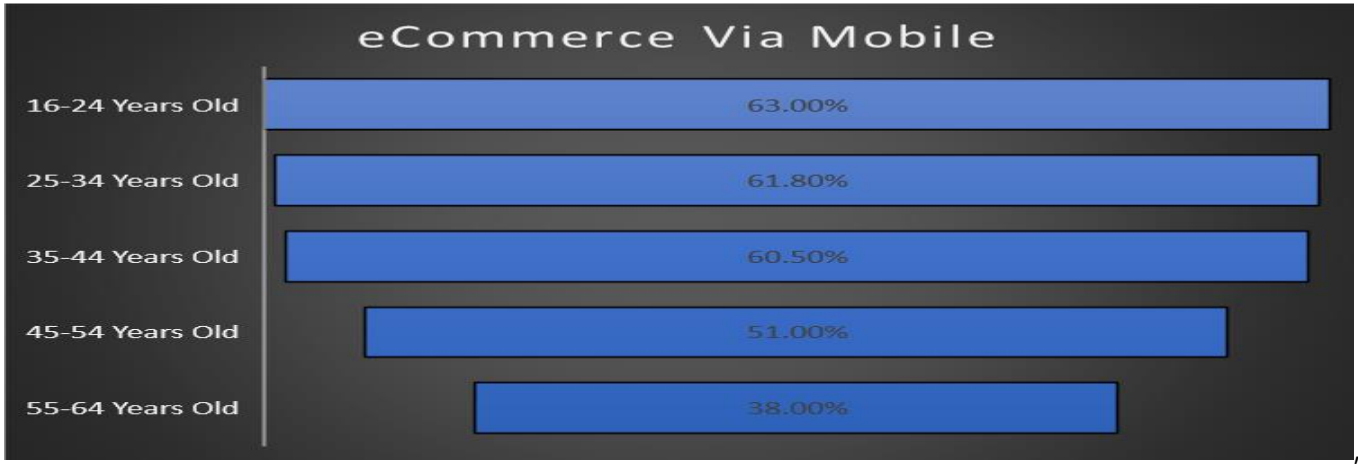

SOURCE: Hootsuite \& We Are Social (2021), "Digital 2021 Global Digital Overview," 
In below figure 3, consumer preferences work in the opposite direction. While the oldest population performs most of the transactions via computer, the youngest generation has less use of computers. We can link this to the fact that the younger generation has more interaction with mobile phones due to their mobility features; thus, it can be taken anywhere. Doing shopping through mobile is therefore much more beneficial for the younger generation.

Figure 3: eCommerce Adoption by Age via Computer

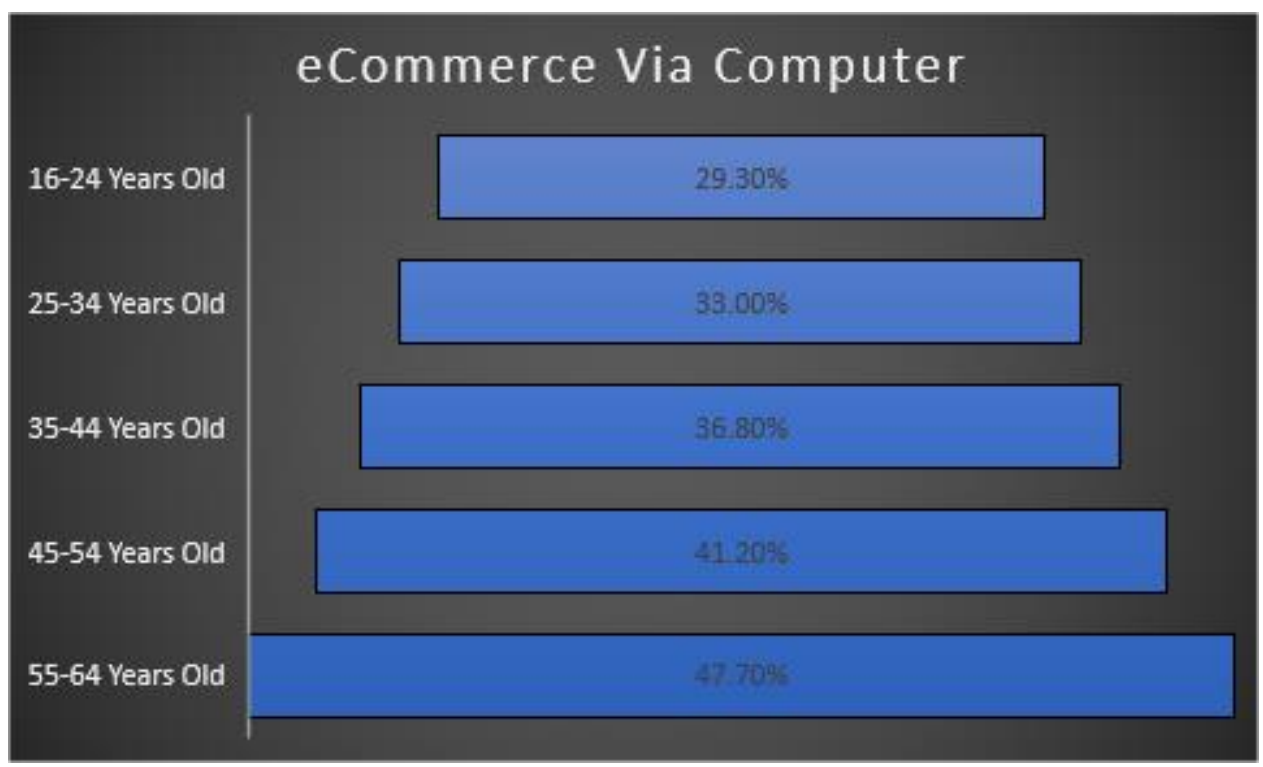

SOURCE: Hootsuite \& We Are Social (2021), "Digital 2021 Global Digital Overview,"

\subsection{Benchmark study}

The Digital Economy and Society Index (DESI) is a composite index that summarizes relevant indicators on Europe's digital performance and tracks the evolution of EU Member States in digital competitiveness. (ec.europa.eu)

DESI overall index, calculated as the weighted average of the five main DESI dimensions: Connectivity (25\%), Human Capital (25\%), Use of Internet (15\%), Integration of Digital Technology (20\%), and Digital Public Services (15\%)

Index Indicators:

Connectivity: DESI Connectivity Dimension calculated as the weighted average of the five sub-dimensions: Fixed Broadband take-up (25\%), Fixed broadband coverage (25\%), Mobile broadband (35\%), and Broadband price index (15\%).

Human Capital: DESI Human Capital Dimension calculated as the weighted average of the two sub-dimensions: Internet User Skills (50\%) and Advanced Skills and Development $(50 \%)$

Use of Internet Services: DESI Use of Internet Dimension calculated as the weighted average of the three sub-dimensions: Internet Use (25\%), Activities Online (50\%), Transactions (25\%)

Integration of Digital Technology: DESI Integration of Digital Technology Dimension calculated as the weighted average of the two sub-dimensions: Business digitization $(60 \%)$ and e-Commerce $(40 \%)$.

Digital Public Services: DESI Digital Public Services Dimension calculated by taking the score for e-Government.

Source: (digital-agenda-data.eu) 
Figure 4: DESI Growth of the Given Countries

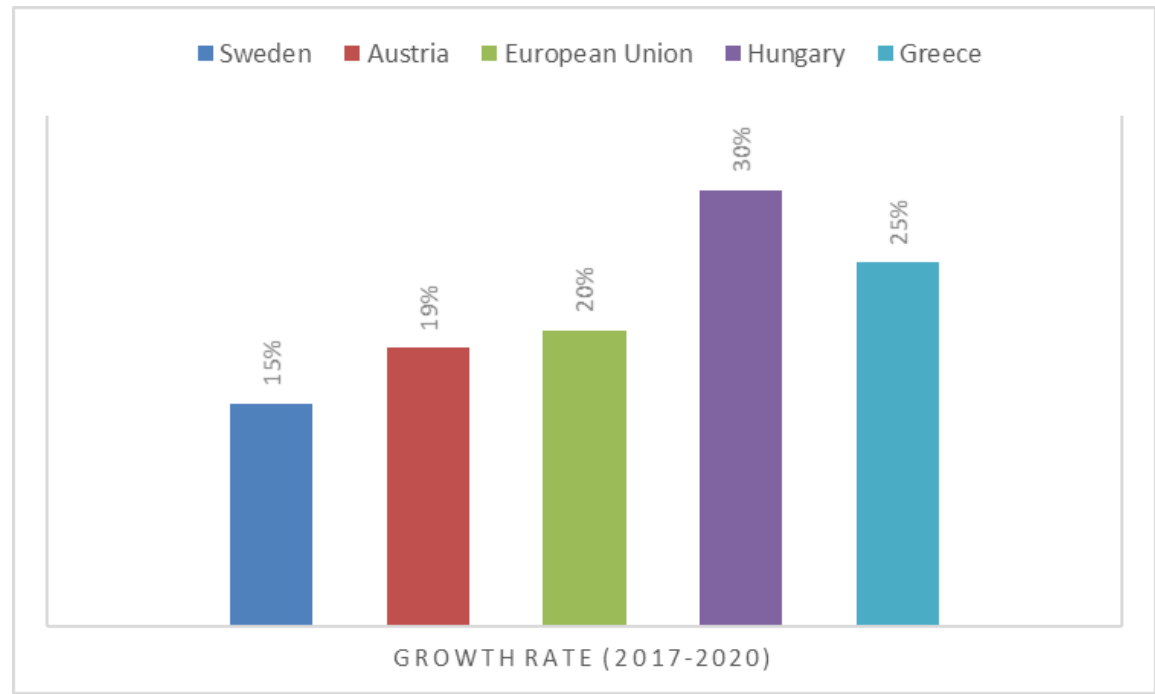

Source: Authors own figure (Extracted from ec.europa.eu)

We used 2017 and 2020 Index Scores to calculate the growth rate of the countries in the last four years. We can see that Hungary takes the lead in terms of growth with a 30 percent of increase from 2017 to 2020. It is followed by Greece with a 25 percent growth rate. They both performed above the EU Average. Therefore, we can assess their growth as a success. Austria's performance stands at 19 percent while the EU average is 20 percent. Austria's rank is 14 in the DESI; therefore, its performance can be assessed as steady but we would assess it progressive if it was above EU Average. As of last, Sweden that ranks as the third-best country in DESI performs quite well considering the current position of the country in the list. The growth rate is nearly close to EU Average.

Figure 5: Desi Index Scores for Sweden between 2017 to 2020:

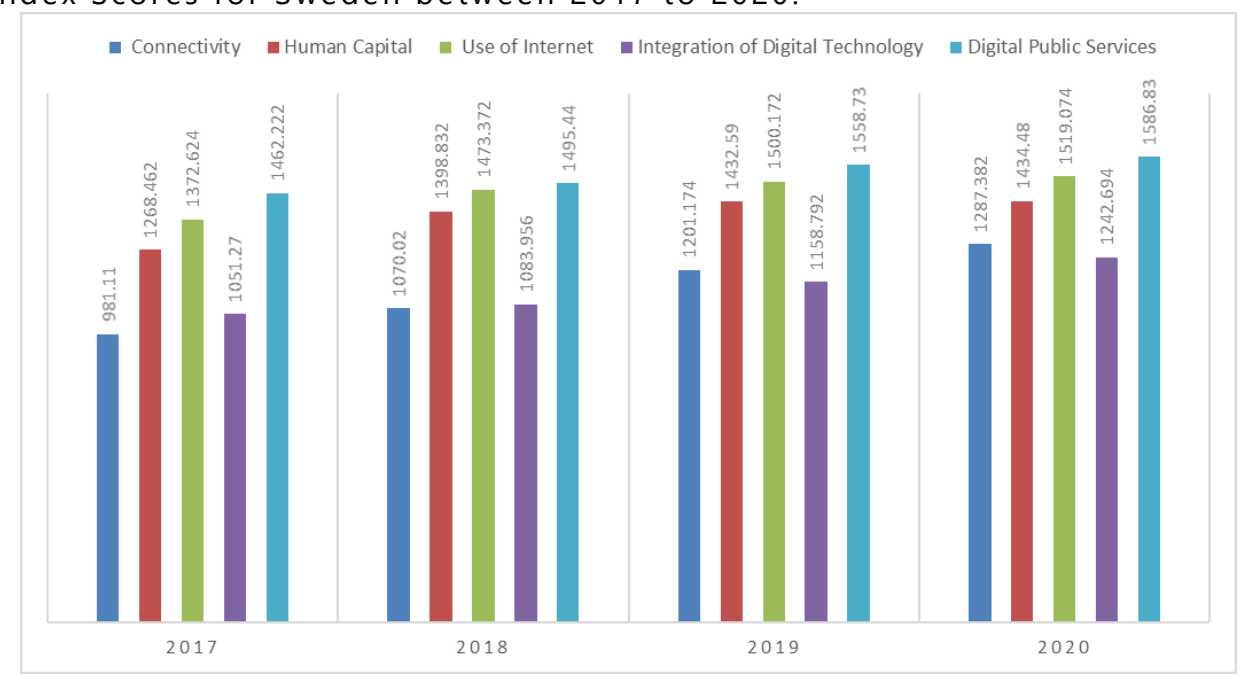

Source: Authors own figure (Extracted from ec.europa.eu)

Starting from 2017, we can see that Digital Public Services is the best indicator contributing to Sweden's index. While Human Capital and Use of the Internet remain competitive, Internet usage is the second-best contributor for the Index Score. Furthermore, Integration of Digital Technology starts as the third-best contributor to the index. We can see that from 2019, the Connectivity indicator takes third place for the best contributor for the Index. 
Figure 6: Index Performance of Austria between 2017 - 2020

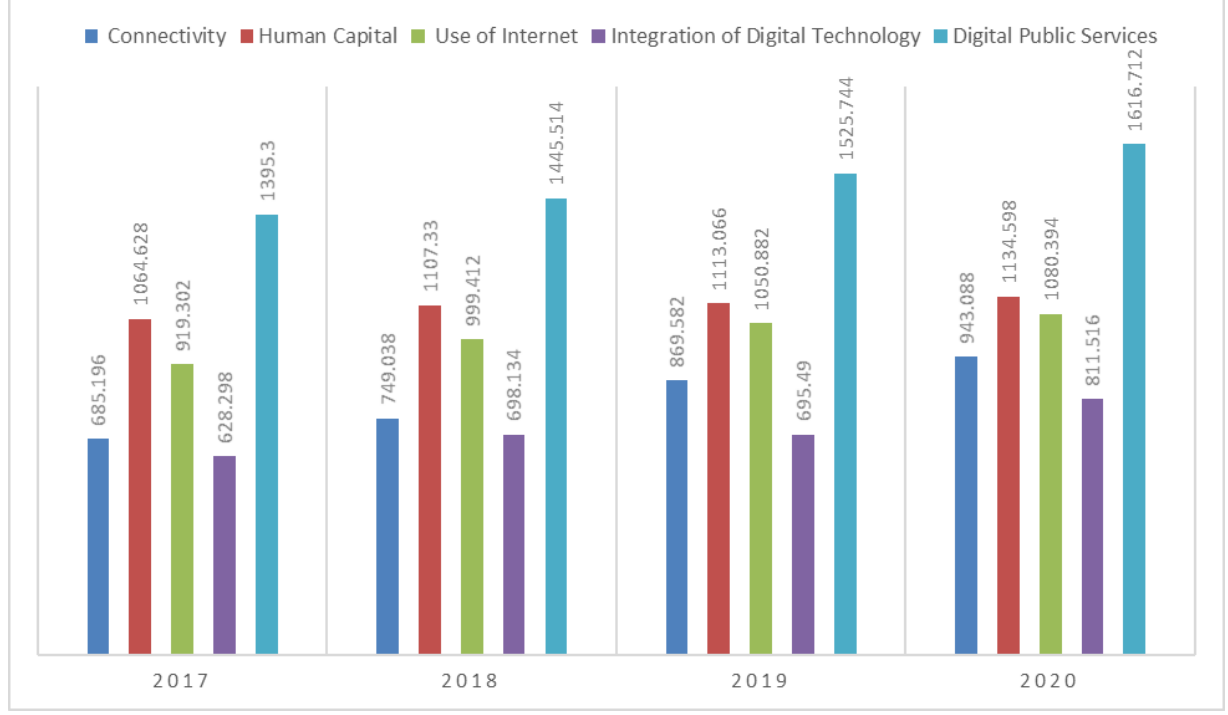

Source: Authors own figure (Extracted from ec.europa.eu)

Starting from 2017, we can see that Digital Public Services is the best indicator contributing to Austria for the index for the entire period. While Human Capital is the second-best contributor for the Index Score. Moreover, the Connectivity indicator has increased remarkably in the last four years. In our view, what slows down Austria's performance in the Index is the integration of digital technology. Even though it also increased in the last four years, the overall score is less satisfying than Digital Public Services. Therefore, we conclude that more investment is needed for the digitization of businesses.

Figure 7: Index Performance of Hungary between 2017 - 2020

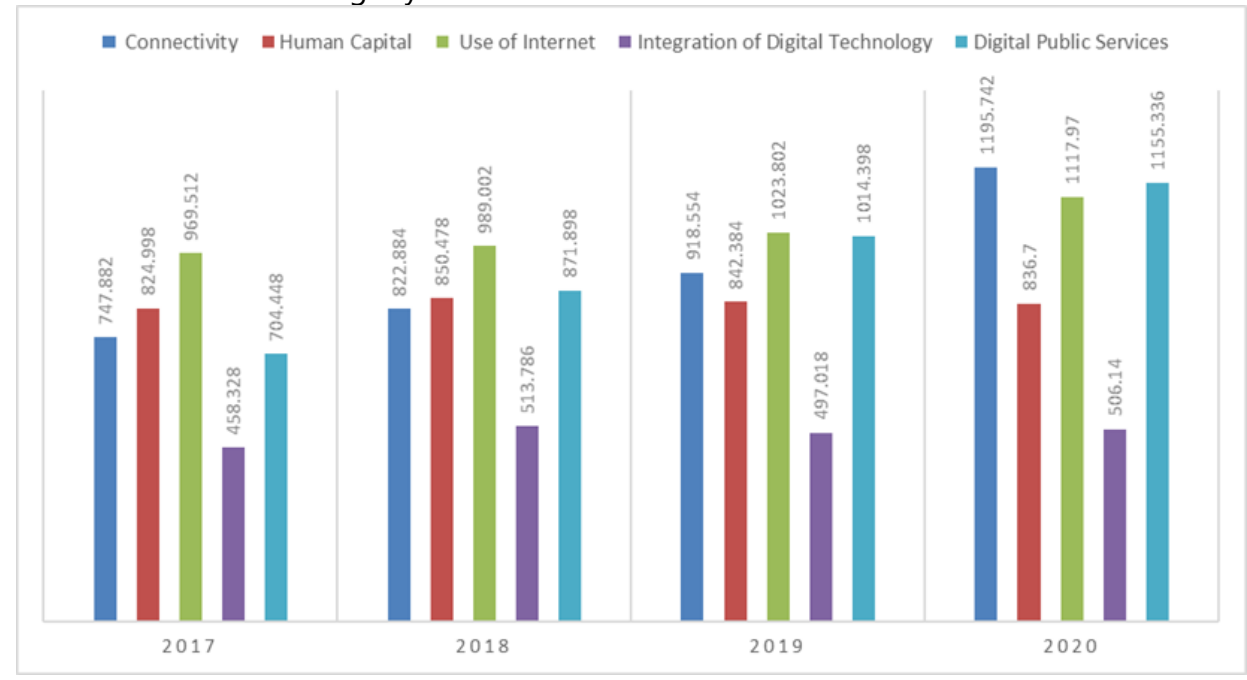

Source: Authors own figure (Extracted from ec.europa.eu)

Hungary is ranked the 22 nd in the DESI. However, it has the best growth rate among other countries. It has 30 percent growth rate in the last four years. It is important to state that Hungary performed an enormous growth in Connectivity and Digital Public Services. The Connectivity level increased by 60 percent in the last four years while Digital Public Services increased by 64 percent. Therefore, we can conclude that government initiatives and investments were very successful in this matter. On the other hand, Human capital remained nearly the same in the last four years, which means that the digital readiness level of the society did not show significant progress. The Integration of Digital Technology holds back Hungary since it contributes the least to the Index score. We suggest companies invest more in digitalization for Hungary. As potential results of suggestion, we believe that Human Capital 
will grow organically since Government and Business offers digital services, society will have to adapt with time.

Figure 8: Index Performance of Greece between 2017 - 2020

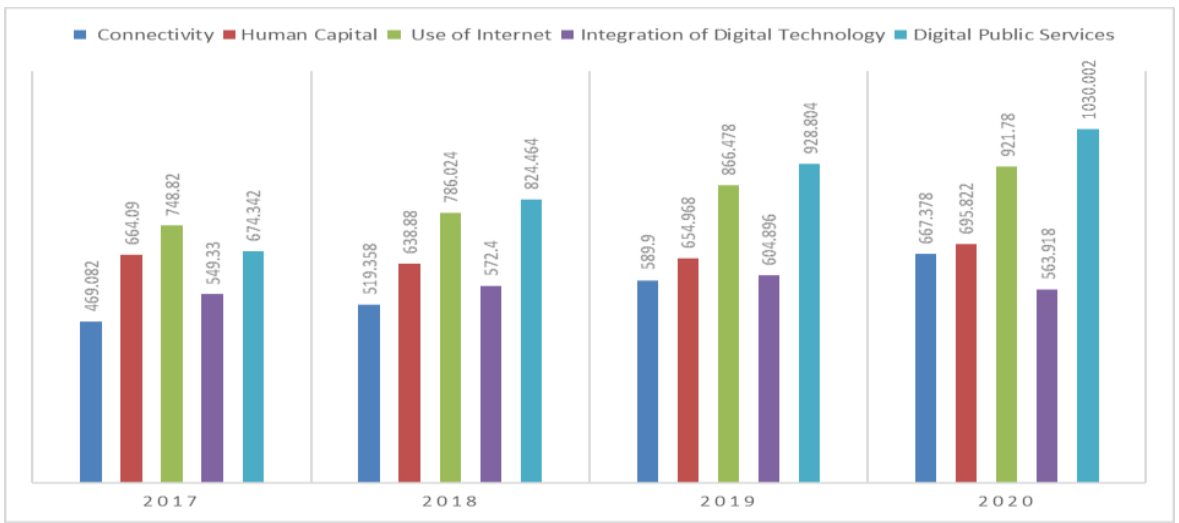

Source: Authors own figure (Extracted from ec.europa.eu)

Greece is the 28th country in the DESI Index. In 2017, the best contributor was the use of the Internet. However, starting from 2017 until 2020, we can see an increasing trend in Digital Public services, and start from 2018, it takes the lead of being the most contributor for the Index Score of Greece. However, the use of the Internet remains the second-best contributor until 2020. Even though we see some development in the Connectivity indicator, Greece has to invest in digital infrastructure and promote more and more digital services to society.

\subsection{Benchmark of Financial Inclusion Factors:}

Figure 9: Financial Inclusion Factors of the selected countries.

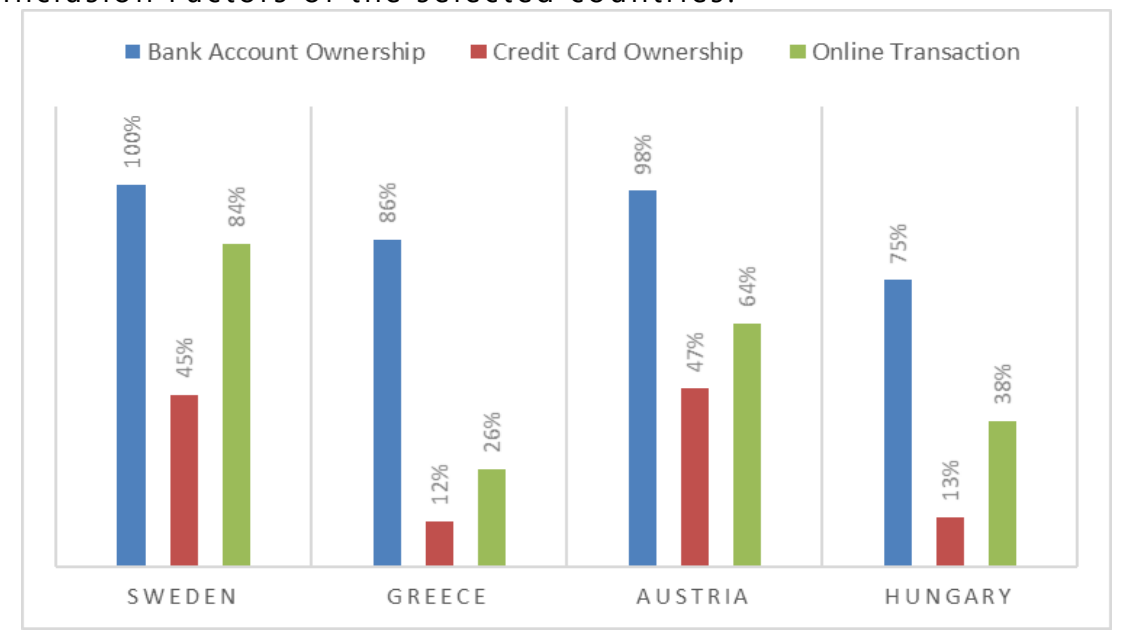

Source: Self-made (Data: World bank, 2017)

Financial Inclusion Factors in Sweden and Austria are close to perfect. Nearly all people have a bank account and the online transaction rate is very high. On the other hand, in Hungary, only 75 percent of the people hold a bank account online transaction rate is 38 percent. Greece, as the last country has 86 percent of bank account holders with 26 percent of the online transaction. With the given data we can clearly say that DESI is aligned with Financial Inclusion Factors because Sweden performs nearly perfectly here while it ranks as the third-best country in DESI. On the other hand, Greece performs nearly the least in DESI and here, we can see that the online transaction rate is the lowest among all others. Therefore, we can say that the ranking of financial inclusion factors in this figure is highly aligned with DESI Scores. Furthermore, it is important to state that numbers are from 2017. Further investigation is suggested after the post-covid numbers are available. 
Table 2: Benchmark of the Ecommerce Growth's by Category (In USD):

(Full-year data of 2019-2020)

\begin{tabular}{|llllll|}
\hline Countries & Travel \& Mobility & Fashion & Electronics & Food \& Care & Furniture \\
\hline Sweden & $5.24 \mathrm{BN}$ & $3.68 \mathrm{BN}$ & $2.64 \mathrm{BN}$ & $1.19 \mathrm{BN}$ & $1.191 \mathrm{BN}$ \\
\hline Sweden Growth (\%) & -40 & 22 & 17 & 22 & 22 \\
\hline Austria & $2.93 \mathrm{BN}$ & $2.13 \mathrm{BN}$ & $1.87 \mathrm{BN}$ & $646 \mathrm{MN}$ & $992 \mathrm{MN}$ \\
\hline $\begin{array}{l}\text { Austria Growth (\%) } \\
\text { Hungary }\end{array}$ & -50 & 18 & 14 & 28 & 18 \\
\hline $\begin{array}{l}\text { Hungary Growth } \\
\text { (\%) }\end{array}$ & $-479 \mathrm{MN}$ & $583 \mathrm{MN}$ & $365 \mathrm{MN}$ & $217 \mathrm{MN}$ & $125 \mathrm{MN}$ \\
\hline $\begin{array}{l}\text { Greece } \\
\text { Greece Growth (\%) }\end{array}$ & -47 & 34 & 37 & 41 & 38 \\
\hline
\end{tabular}

Source: Source: Self-made (Data: Hootsuite \& We Are Social (2021)

Travel and mobility sectors of the countries have plummeted around 45 percent due to international flight bans and country-wide curfews. On the other hand, the Fashion sector growth rate is the highest for Hungary with 34 percent; however, in eCommerce value, Sweden has the biggest growth with 810 MN USD year to year change.

Consumer electronics sector growth has remained lower than the Fashion sector for all countries except Hungary, with a 37 percent growth rate surpassing the Fashion sector by 3 percent. As for the Food sector, Hungary again performed the best growth rate with 41 percent followed by Greece with 38 percent. Lastly, Furniture sector growth's shows similar reactions as the previous ranking since Hungary performed 38 percent growth followed by Greece with 30 percent.

Overall, between 2019 and 2020, we can conclude that the food sector has the biggest growth rate of all, followed by the furniture and fashion sectors.

These results can be interpreted as the covid19 pandemic, influenced eCommerce adoption mostly with food and comfort-related transactions. Change in business models encouraged business professionals to purchase more comfortable furniture for their homes while it becomes their new offices. On the other hand, remote education also encouraged parents and students to invest in more ergonomic furniture since the new classroom become their own room in their houses. Finally, Hungary is the only outlier in the electronics sector while the rest of the countries did not encounter a higher rate of growth in that specific sector. It may be interpreted in a way that Hungarian families are getting more and more digitalized due to curfews and remote education caused by the covid19 pandemic.

Figure 10: Digital Payments

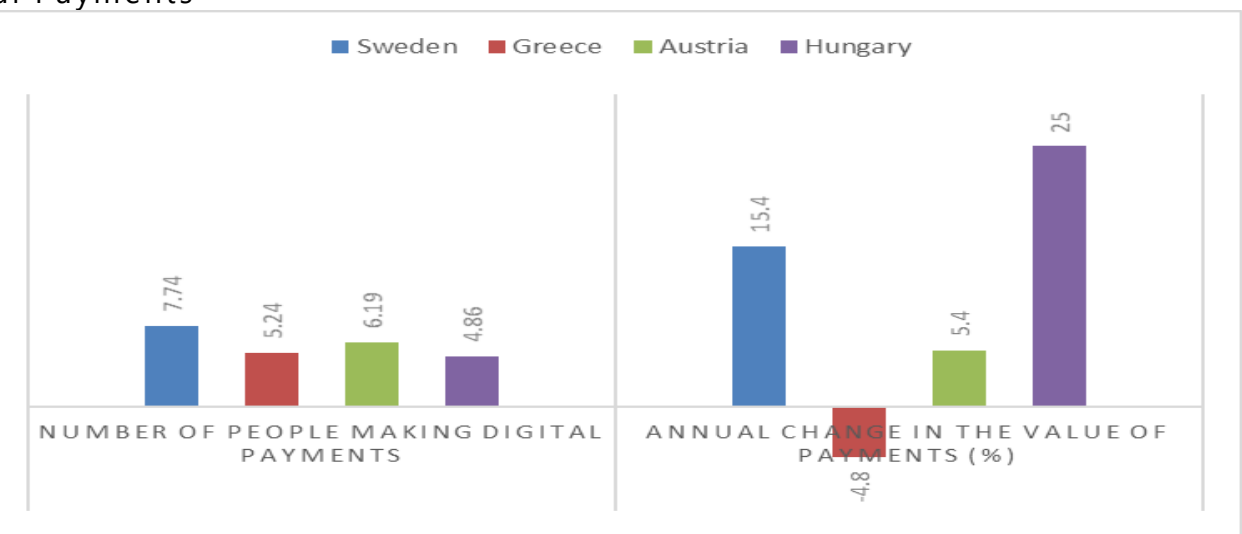

Source: Self-made (Data: Hootsuite \& We Are Social (2021)) 
When we compare results of the digital payments conducted by the number of people which is on the left side of the figure. We can clearly see that Sweden and Austria are the top performers again.

However, when we look at the right side of the figure for the annual change in the value of the payments, we can see that Hungary's growth is notably high with 25 percent annual change while we can see that the annual change for Greece is nearly minus 5 percent. Therefore, we expect Hungary to pass Greece in this matter and get closer to the level of Austria in several years.

Figure 11: eCommerce Spend of Selected Countries: (in Million Dollars)

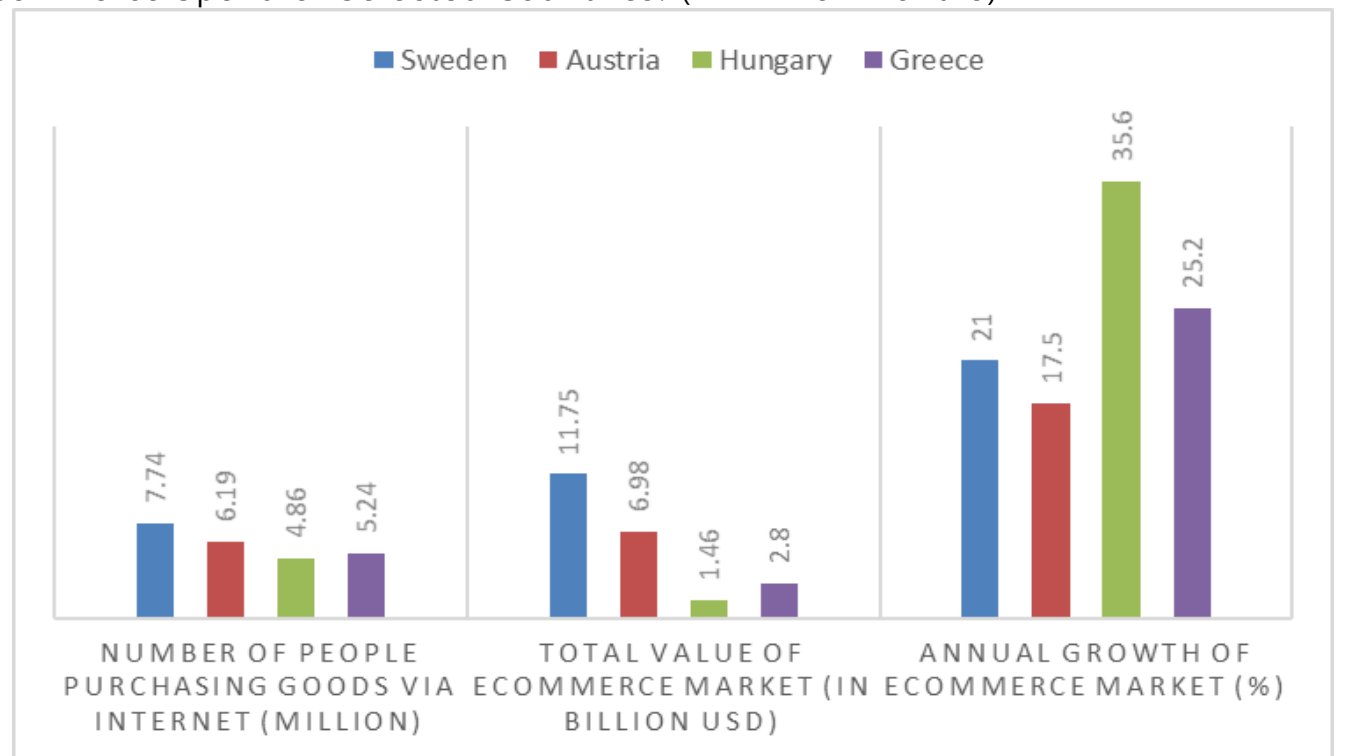

Source: Self-made (Data: Hootsuite \& We Are Social (2021

Sweden performs the best in ratios both in the number of people and eCommerce value. Austria performs as the second-best in terms of the given attributes. However, Hungary remains the least performer country in the first two indicators. Surprisingly, Hungary performs the best growth for the annual change in eCommerce with a 35.6 percent growth for the eCommerce transactions.

Figure 12: ONLINE FOOD DELIVERY

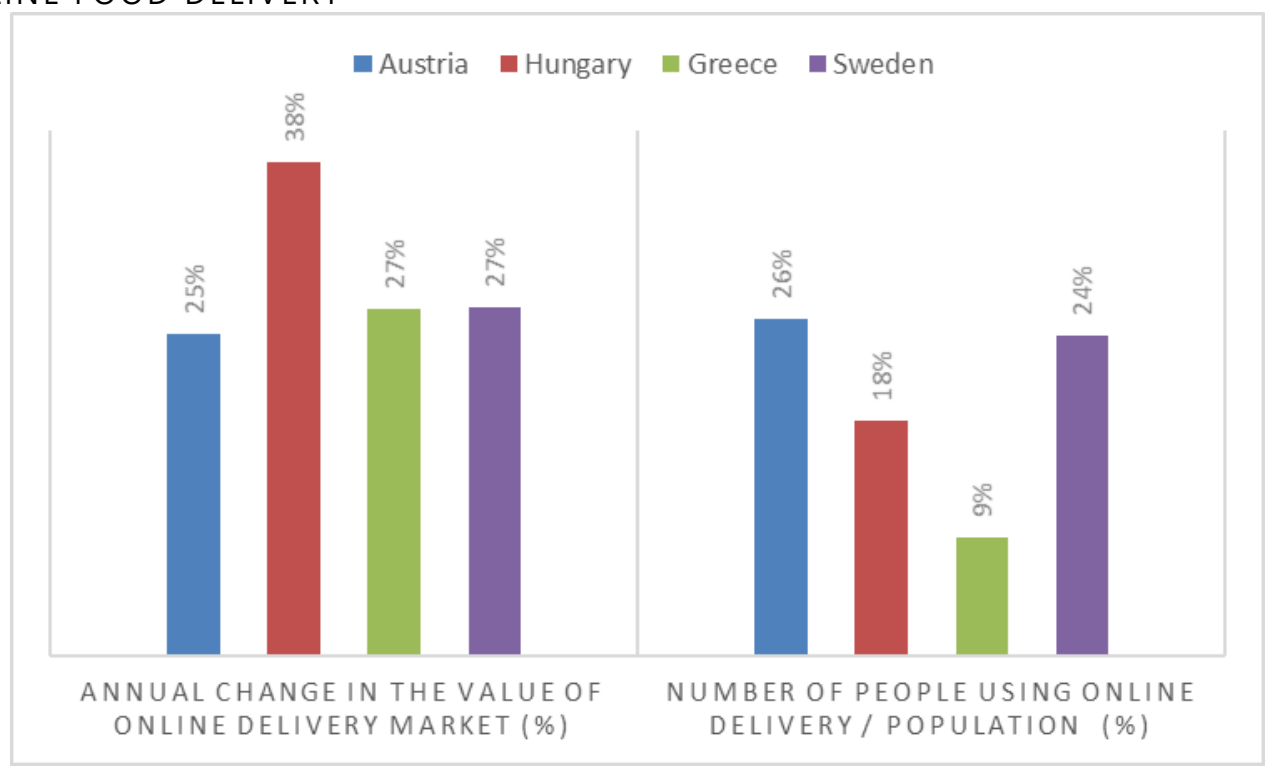

Source: Self-made (Data: Hootsuite \& We Are Social (2021)) 
While all three countries remain around the same growth rate, Hungary performs a 38 percent annual change in the value of the online delivery market. On the other hand, it remains as the third with, Online delivery / Population indicator with 18 percent.

\section{Results and Discussion}

Both DESI and eCommerce results of Sweden have shown that the financial inclusion of the country is excellent. In DESI, Digital Public Services is the leading indicator for Sweden to be ranked as one of the top performers while other indicators are being competitive. Therefore, we can assess Sweeden as a digitalized country with its government, businesses, and people.

Both DESI and eCommerce results of Austria have shown that the country's financial inclusion is very good. In DESI, Digital Public Services is also the leading indicator for Austria while Integration of Digital Technology represents the performance of digitalized businesses, and eCommerce performs much weaker than Sweeden. On the other hand, the Connectivity indicator has shown a promising increase; however, it is still lowered than Sweeden and Hungary. Therefore, we can assess Austria as a digitalized country with its government and people where businesses have to invest more into digitalization and eCommerce.

Both DESI and eCommerce results of Hungary have shown that financial inclusion of the country is Moderate comparing to Sweden and Austria, however, it must be kept in mind that the number reflects on 2017 while there is no data available for 2021. In DESI, Connectivity and Digital Public Services are the leading indicators for Hungary where both indicators have performed more than 60 percent growth in the last four years. On the other hand, Human Capital Indicator did not show any growth since 2017 which means that the digital skills and financial literacy of the society are ranged from low to moderate. Furthermore, Integration of Digital Technology, which stands for digitalized businesses and eCommerce, is not performing any better than the above-mentioned countries. Therefore, we can assess Hungary as progressing through digitalization, with its strong government initiatives in digitalization where businesses have to invest more into digitalization and eCommerce and people need to adopt digital skills to efficiently use the offered digital services. We suggest further investigate these results for upcoming DESI results while we believe the Human Capital Indicator of Hungary will increase significantly due to the Covid19 pandemic since the eCommerce results on the above-mentioned figures and tables show that Hungary has the biggest growth rate in all eCommerce related transactions, including online food delivery.

Both DESI and eCommerce results of Greece have shown that the country's financial inclusion is Low to Moderate, compared to Sweden, Austria, and Hungary. In DESI, Use of the Internet and Digital Public Services are the leading indicators for Greece. On the other hand, Human Capital, Connectivity, and Integration of Digital Technology indicators perform very weakly. Therefore, we can assess Greece as slowly- progressing through digitalization, with its government initiatives to offer public services where government needs to invest in infrastructure for Connectivity issues, businesses to invest in digitalization, and people to adopt digitalization.

\section{Conclusion}

Results of the Covid-19 pandemic reflected rapidly on eCommerce adoption all around the world. At the same time, we can see that easing the curfews leads to an immediate decrease in eCommerce transactions. Anyhow regardless of age, the demand for eCommerce has skyrocketed all around the world. While elderly people adopted eCommerce via a desktop PC with their internet, the younger generation preferred to use mobile shopping over the internet.

When we benchmark country performances using DESI Index and economic strength which we assessed using Sovereign credit rating, it can be concluded that economic well-being impacts the countries' DESI Index results. We proved this claim in this paper by comparing four countries with different economic levels and different DESI Scores.

Furthermore, we can say that the DESI index is mostly aligned with eCommerce data of 2020-2021. Countries that provide the best results in DESI Index also provide the best results in eCommerce during the covid19 pandemic while only Hungary stands in a better position in DESI however has less 
eCommerce value then Greece yet eCommerce growth of Hungary has yielded the best results during the pandemic. From this point of view, we can conclude that economic well-being has an impact on the adoption of digital skills where prosperity influences society decisions into more digitalized transactions.

Lastly, we find it essential to state that the numbers and metrics above include the Covid19 pandemic period. However, DESI 2021 results are not released yet. Therefore, a revision might be necessary for the future with DESI-related articles due to the strong impact of Covid19 on financial literacy and eCommerce adoption.

\section{References}

[1] Demirguc-Kunt, A. \& Klapper, L. \& Singer, D. (2017). Financial Inclusion and Inclusive Growth: A Review of Recent Empirical Evidence. 10.1596/1813-9450-8040.

E-COMMERCE TO CONTINUE ITS LEADING ROLE IN ECONOMIC GROWTH | UNCTAD

[2] Link:https://unctad.org/press-material/e-commerce-continue-its-leading-role-economic-growth E-commerce creates a change in the global economy - rawabet center

[3] Link:https://rawabetcenter.com/en/?p=5241

[4] Krechovská, M. "FINANCIAL LITERACY AS A PATH TO SUSTAINABILITY." Trendy v podnikání 5 (2015): $3-12$.

[5] Habschick, M., Seidl, B., \& Evers, J. (2007). Survey of financial literacy schemes in the EU27. VT Markt/2006/26H-Final Report, Hamburg.

[6] OECD (1999-01-01), "Economic and Social Impact of Ecommerce: Preliminary Findings and Research Agenda", OECD Digital Economy Papers, No. 40, OECD Publishing, Paris. Link:http://dx.doi.org/10.1787/236588526334

[7] The Macro-economic Impact of e-Commerce in the EU Digital Single Market (2015) Link:http://ec.europa.eu/jrc/en/publication/eur-scientific-and-technical-research-reports/macro-economic-impact-ecommerce-eu-digital-single-market

[8] Kovács, L., \& Terták, E. (2019). Financial Literacy Theory and Evidence. Verlag Dashöfer, Bratislava.

[9] Liu, S. (2012). An empirical study on e-commerce's effects on economic growth. 0081-0084. 10.1109/NCES.2012.6543371.

[10] Lusardi, Annamaria, and Olivia S. Mitchell. 2014. "The Economic Importance of Financial Literacy: Theory and Evidence." Journal of Economic Literature, 52 (1): 5-44.

[11] Data Source: Hootsuite \& We Are Social (2021), "Digital 2021 Global Digital Overview," retrieved from https://datareportal.com/reports/digital-2021-global-overview-report eCommerce and Digital Report Dataset: https://datareportal.com/reports/?tag= Digital +2021 Desi Dataset: https://ec.europa.eu/digital-single-market/en/digital-economy-and-society-indexdesi 